\title{
OPEN Hydrometallurgical process development to recycle valuable metals from spent SCR deNO catalyst
}

\begin{abstract}
Jong Hyuk Jeon ${ }^{1,3}$, Ana Belen Cueva Sola ${ }^{1,2,3}$, Jin-Young Lee ${ }^{1,2}$ \& Rajesh Kumar Jyothi, ${ }^{1,2}$
Spent catalyst, containing vanadium and tungsten oxide in $\mathrm{TiO}_{2}$ glass fiber matrix, pose a risk of environmental contamination due to the high toxicity of its metal oxides if leached into the soil when disposed in landfills. Due to the increasing demand of metals and the continuous depletion of primary resources there is an growing necessity for recycling and reprocessing of spent catalysts and other secondary metal sources for environmental and economical reasons. Study of spent SCR catalyst soda roasting process with dissolved $\mathrm{NaOH}$ compared with the usual $\mathrm{NaOH}$ dry roasting and its influence in the subsequent water leaching. After optimization, the ideal parameters are roasting using a 0.4 ratio of $\mathrm{NaOH} / \mathrm{spent} \mathrm{SCR}$ catalyst in solution for $2 \mathrm{~h}$ at $973 \mathrm{~K}$ and de-ionized water leaching for $30 \mathrm{~min}$, at $298 \mathrm{~K}$ with a pulp density of $30 \%$. The research results show an important reduction of the roasting temperature and leaching time during the processing of spent SCR catalyst obtaining a $95.4 \% \mathrm{~W}$ and $80.2 \% \mathrm{~V}$ leaching efficiency liquor. Silicon compounds are one of the main impurities leached alongside the valuable metals and in this work, the silicon compounds leached are reduced significantly with the aim of avoiding the de-silication post-processing of the leach liquor. The main advantage of the proposed process is the increase of the leaching efficiency of vanadium and tungsten with a minimization of silicon impurities in a shorter time regardless of the leaching temperature.
\end{abstract}

From the 2000s (new millennium) the increasing concerns about environmental pollution caused by nitrogen oxides has directly influenced a higher production and demand for selective catalytic reduction (SCR) catalysts for the minimization of the NOx discharged from a variety of sources (stationary and mobile) worldwide ${ }^{1-3}$. Thus, the amount of waste from catalysts generated by increasing the amount of SCR catalysts produced is also increasing ${ }^{4,5}$. Until now, spent SCR catalysts that have been deactivated by poisoning have been regenerated and reused until the activity is reduced, when most of them are disposed in landfills with designated waste based on each country's regulations $s^{6-8}$. However, the composition of the spent catalyst possess another environmental threat when it is disposed or buried due to the accumulation and leaching of $\mathrm{V}_{2} \mathrm{O}_{5}$, a highly toxic compound alongside other heavy metals. In addition, the deactivated catalyst cannot be directly reprocessed as a new catalyst carrier because of the high content of $\mathrm{As}, \mathrm{Na}, \mathrm{Ca}, \mathrm{Fe}$ and $\mathrm{K}$ and its vulnerability to chemical toxicity ${ }^{9-11}$. One of the most common and effective catalyst are SCR catalysts consisting of $\mathrm{V}_{2} \mathrm{O}_{5}-\mathrm{WO}_{3} / \mathrm{TiO}_{2}$ which, generally have very high $\mathrm{Ti}, \mathrm{W}$ and $\mathrm{V}$ content, consequently it can be an economic and environmental feasible option to recover and reuse them. Ti, W, and V remanufactured after recovery can be used as raw materials for new catalysts or as raw materials in other industries ${ }^{4,12,13}$. Accordingly, technology development studies are actively being conducted to recover and remanufacture raw materials from spent catalysts ${ }^{14}$. A variety of hydrometallurgical methods for the recycle of titanium, tungsten and vanadium from spent SCR catalysts are widely known, and they consist in the preparation of a leachate by soda-roasting ${ }^{15}$, pressurized $^{16}$ or acid and alkali leaching, and then purified to obtain the valuable metals in the solution ${ }^{17}$.

Wu et al. (2016) studied the reprocessing of tungsten from spent SCR catalyst (honeycomb type) by alkali leaching-ion exchange method. The spent catalyst samples of $74 \mu \mathrm{m}$ particle size were leached at a high liquid ratio of $3 \%$ and a reaction temperature of $70{ }^{\circ} \mathrm{C}$ for $30 \mathrm{~min}$, respectively, and $91 \mathrm{wt} \%$ and $87 \mathrm{wt} \%$ of $\mathrm{W}$ and $\mathrm{V}$ were leached, respectively. The leachate was adsorbed using a strong base anion exchange resin (Amberlite IRA900),

${ }^{1}$ Convergence Research Center for Development of Mineral Resources (DMR), Korea Institute of Geoscience and Mineral Resources (KIGAM), Daejeon 34132, Korea. ${ }^{2}$ Department of Resources Recycling, Korea University of Science and Technology (UST), Daejeon 34113, Korea. ${ }^{3}$ These authors contributed equally: Jong Hyuk Jeon and Ana Belen Cueva Sola ${ }^{\varpi}$ email: rkumarphd@kigam.re.kr 
and the divalent $\mathrm{WO}_{4}{ }^{-}$was selectively separated under high $\mathrm{pH}$ conditions ${ }^{18}$. Choi et al. $(2019,2018 \mathrm{a})$ performed soda-roasting experiments with $\mathrm{Na}_{2} \mathrm{CO}_{3}$ to react with the spent SCR catalysts. The amount of $\mathrm{Na}_{2} \mathrm{CO}_{3}$ was 10 equivalent and the spent SCR catalyst with a particle size of less than $106 \mu \mathrm{m}$ was roasted at $1070 \mathrm{~K}$ for $120 \mathrm{~min}$. In this study, it was found that the increase of the amount of tungsten leached was related to the inhibition of $\mathrm{CaWO}_{4}$ production due to the increase of $\mathrm{Na}_{2} \mathrm{CO}_{3}$ addition along with the rate of $\mathrm{TiO}_{2}$ anatase changing phases to rutile. In contrast, the amount of vanadium leached was not influenced by the amount of sodium carbonate, and the results of the experiment showed an approximate constant rate of about $40 \%$. This was attributed to the production of calcium vanadium acid when reacting with $\mathrm{CaO}$ present in the raw material, and the leaching ability of $\mathrm{V}$ was obtained analyzing the amount of calcium in the raw material ${ }^{2,10,15}$. Wu et al. (2018) examined the selective leaching and reaction mechanisms of $\mathrm{V}$ and $\mathrm{Fe}$ using oxalic acid. The experiment was performed for $180 \mathrm{~min}$ under the condition of a reaction temperature of $90^{\circ} \mathrm{C}$, a high liquid ratio of $20 \mathrm{~mL} / \mathrm{g}$, and the particle size of $75 \mu \mathrm{m}$ using $1.0 \mathrm{~mol} / \mathrm{L}$ concentration of oxalic acid, the results showed a $84 \%$ of $\mathrm{V}$ and $96 \%$ of Fe leached. The soluble cations $\mathrm{VO}_{2}{ }^{+}$and $\mathrm{Fe}^{3+}$ were reduced through the dissolution and complexation process in the leaching reaction. $\mathrm{V}$ and $\mathrm{Fe}$ were found to yield a high leaching when they were present in certain forms of $\mathrm{VOC}_{2} \mathrm{O}_{4}$ and $\mathrm{Fe}\left(\mathrm{C}_{2} \mathrm{O}_{4}\right)_{2}$ at $0.33 \mathrm{pH}$, which showed that the oxidation reduction reaction resulted in the destruction of the dissolution and complexing equilibrium for $\mathrm{VO}^{2+}, \mathrm{VO}^{+}$and $\mathrm{Fe}^{3+}$. In the case of tungsten and titanium, only the dissolution and complexation reaction occurred and the leaching efficiency was hindered by solubility ${ }^{19}$.

However, in previous studies, if a large amount of $\mathrm{SiO}_{2}$ is leached together with vanadium and tungsten, there is a competitive leaching process where vanadium and tungsten leaching could be inhibited by the presence of silicon. In addition, after leaching for separation of the title metals by ion-exchange or solvent extraction, silicon must be removed adding an extra step to the recovery and purification process ${ }^{15,20-22}$.

In this study, we performed a hydrometallurgical process through soda roasting and water leaching for the recovery of vanadium (V) and tungsten (W) from spent SCR deNO $\mathrm{x}_{\mathrm{x}}$ catalysts. The leaching efficiency of vanadium, tungsten and the silicon impurity was compared based on the premise that the phase of the roasting agent, either $\mathrm{NaOH}$ solid or $\mathrm{NaOH}$ solution, affects the leaching conditions of the title metals and the amount of silicon impurity leached. The optimum leaching condition is derived based on the roasting agent amount, temperature and time. For water leaching the parameters to consider are solid liquid ratio, the reaction temperature, and reaction time.

\section{Results and discussion}

In the soda roasting process, vanadium and tungsten react with $\mathrm{NaOH}$ to form the water-soluble compounds $\mathrm{NaVO}_{3}$ and $\mathrm{Na}_{2} \mathrm{WO}_{4}$ as shown in reaction 1 and 2 . However, in the spent SCR catalysts, in addition to vanadium and tungsten, acting as the main catalytic agents, there is a glass fiber matrix that improves the mechanical properties of the catalyst and its mainly formed of $\mathrm{SiO} 2$, therefore $\mathrm{Na}_{2} \mathrm{SiO}_{3}$ is generated (reaction 3) during the roasting process. Being $\mathrm{Na}_{2} \mathrm{SiO}_{3}$ a water soluble compound it is leached alongside $\mathrm{V}$ and $\mathrm{W}$ which could possibly inhibit or reduce the leaching efficiency of the valuable metals. As a result, the amount of vanadium and tungsten leached decreases due to the presence of silicon soluble compounds. Su et al. (2018) studied the thermodynamics of the three reactions shown below and established that all of the standard free Gibbs energies for the reactions are negative, which indicates spontaneity in the production of the sodium salts, however for temperatures between 0 and $200{ }^{\circ} \mathrm{C}$ the most favorable reaction is the vanadium reaction followed by tungsten and silicon ${ }^{23}$.

Therefore, an experiment was performed to reduce the leaching rate of $\mathrm{SiO}_{2}$ while maximizing the leaching conditions for vanadium and tungsten.

$$
\begin{aligned}
& \mathrm{V}_{2} \mathrm{O}_{5}+2 \mathrm{NaOH} \rightarrow 2 \mathrm{NaVO}_{3}+\mathrm{H}_{2} \mathrm{O} \\
& \mathrm{WO}_{3}+2 \mathrm{NaOH} \rightarrow \mathrm{Na}_{2} \mathrm{WO}_{4}+\mathrm{H}_{2} \mathrm{O} \\
& \mathrm{SiO}_{2}+2 \mathrm{NaOH} \rightarrow 2 \mathrm{Na}_{2} \mathrm{SiO}_{3}+\mathrm{H}_{2} \mathrm{O}
\end{aligned}
$$

$\mathrm{NaOH}$ phase and temperature effect. In the soda roasting process, the reaction temperature is a very important factor in the conversion of $\mathrm{V}_{2} \mathrm{O}_{5}$ and $\mathrm{WO}_{3}$ to $\mathrm{NaVO}_{3}$ and $\mathrm{Na}_{2} \mathrm{WO}_{4}$ from the feedstock. An experiment was conducted to determine the effect of the phase and reaction temperature of $\mathrm{NaOH}$ used as a roasting agent in the amount of vanadium, tungsten and silicon present in the leaching solution. $15 \mathrm{~g}$ of $\mathrm{NaOH}(50 \%$ of the feedstock) were added as a solid to the spent SCR catalyst sample and roasted at $773 \sim 1173 \mathrm{~K}$ for $2 \mathrm{~h}$ while $15 \mathrm{~g} \mathrm{NaOH}$ were dissolved in a sufficient amount of water and subjected to the same roasting temperatures. After roasting, the residue leached in $100 \mathrm{~mL}$ of distilled water at $298 \mathrm{~K}$ for $3 \mathrm{~h}$, pulp density $=30 \%$. As shown in Fig. 1a, the leaching efficiency of vanadium and tungsten augmented as the roasting temperature increased. When using dissolved $\mathrm{NaOH}$ as a roasting agent, the leaching rate was very low at $773 \mathrm{~K}$, but it increased significantly at $873 \mathrm{~K}$, and it was found to reach the maximum at $973 \mathrm{~K}$. On the other hand, when the roasting agent is solid $\mathrm{NaOH}$, the reaction starts after $\mathrm{NaOH}$ melting resulting in a lower leaching efficiency of the title metals. Moreover, dissolved $\mathrm{NaOH}$ has superior mass transfer activity with vanadium and tungsten in the spent catalyst and the ionized sodium ions have a higher reaction surface with the spent catalyst particles than $\mathrm{NaOH}$ in the molten state. Figure 1a shows that the leaching ability of vanadium and tungsten is maximized when the roasting agent is $\mathrm{NaOH}$ solution, while Fig. $1 \mathrm{~b}$ shows that at the same roasting temperature $(973 \mathrm{~K})$ the concentration of silicon leached in the solution is almost half than in the case of $\mathrm{NaOH}$ solid used as a roasting agent. The leaching of Si compounds shows that at a higher roasting temperature the amount of Si leached also increases, therefore a lower soda roasting temperature is preferable for the minimization of silicon leaching impurities. 
(a)
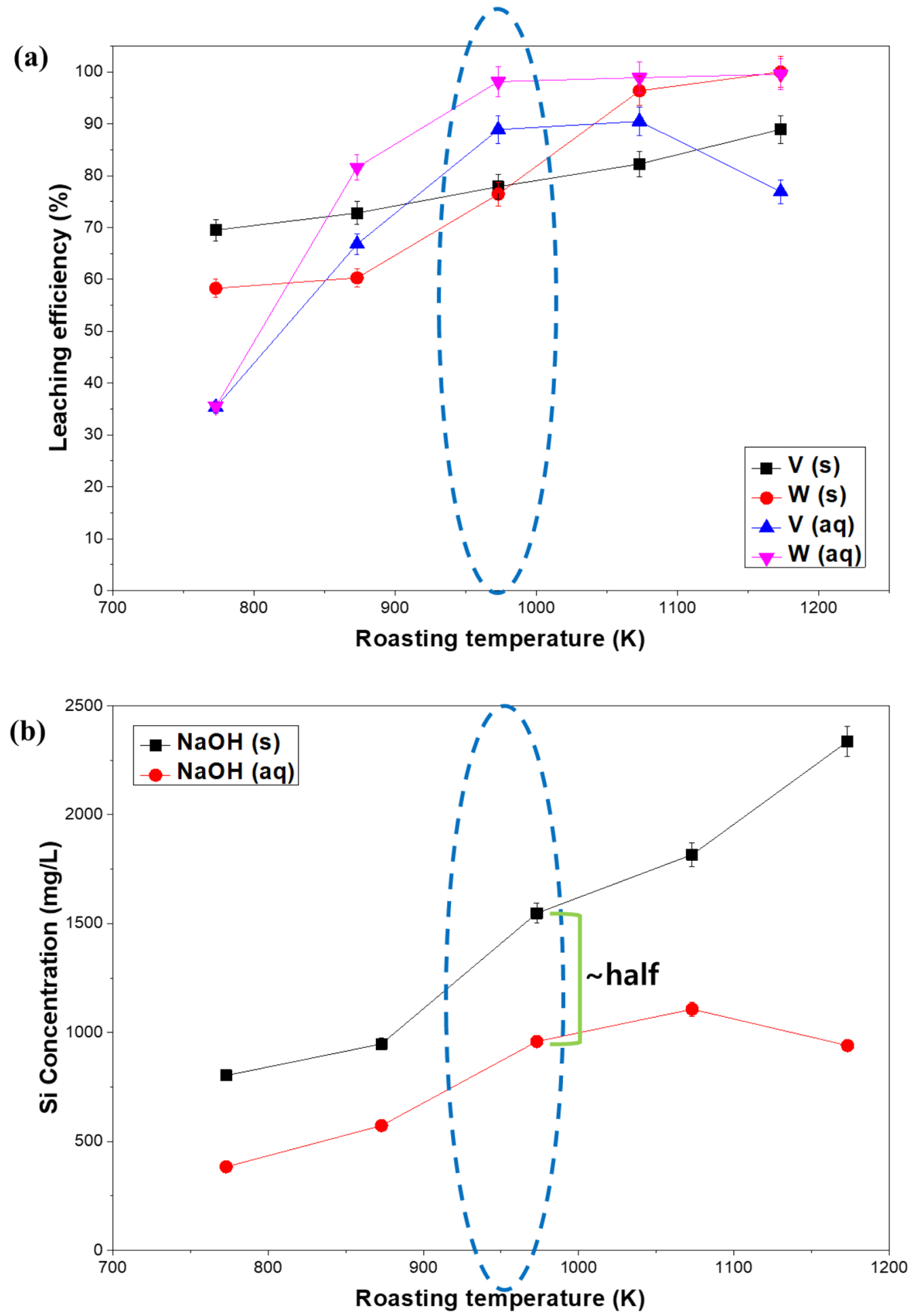

Figure 1. Effects of temperature at the time of roasting process ( $s=$ solid, aq=aqueous) in the (a) leaching of vanadium and tungsten and $(\mathbf{b})$ in the concentration of Si leached.

Effect of sodium hydroxide amount. An experiment was conducted by adding the same mass amount of spent SCR catalyst with an aliquot of $\mathrm{NaOH}$ (dissolved in enough water) at different ratios ranging from 0.1 to 0.5 of the feedstock to compare the leaching efficiency of vanadium and tungsten. The mixture of $\mathrm{NaOH}$ aqueous solution and feedstock was roasted in a muffle furnace for $2 \mathrm{~h}$ at $973 \mathrm{~K}$, and after roasting; the sample was added to distilled water and leached at $278 \mathrm{~K}$ for $3 \mathrm{~h}$ with a pulp density of $30 \%$. The amount of vanadium and tungsten leached according to each experimental condition is shown in Fig. 2a. As the concentration of $\mathrm{NaOH}$ augmented, the leaching efficiency of vanadium and tungsten was greater. When the ratio of $\mathrm{NaOH} /$ spent SCR 
(a)

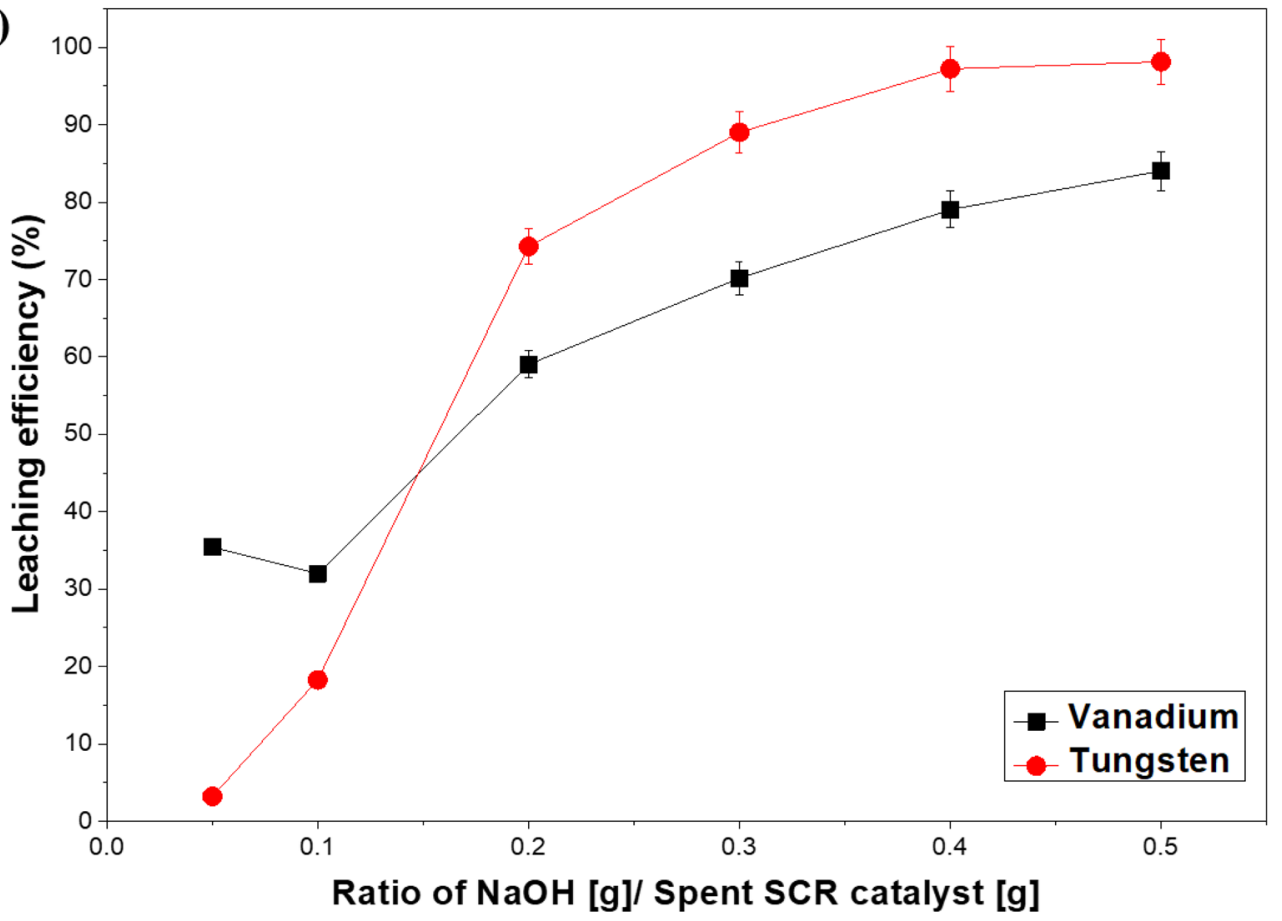

(b)

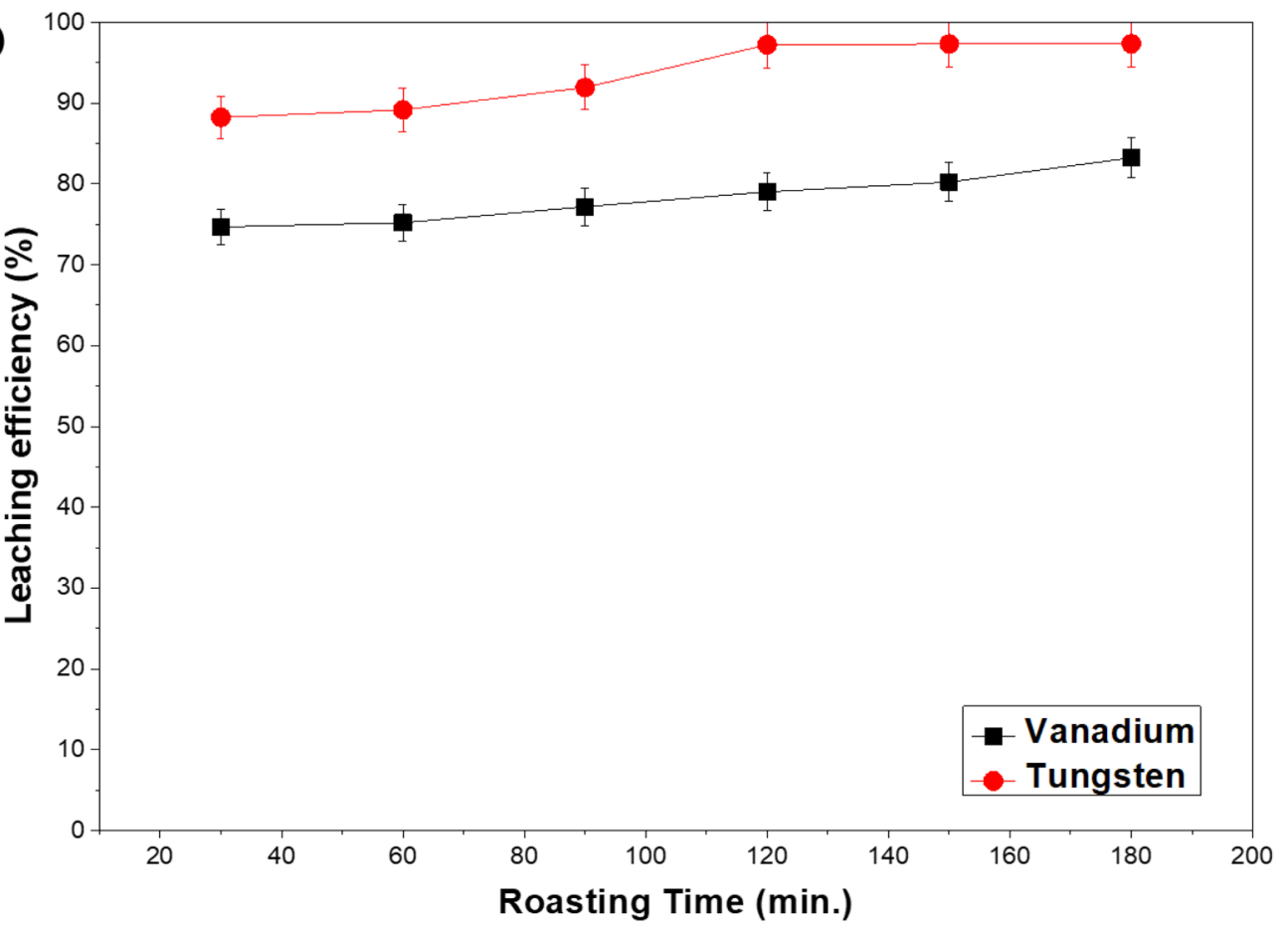

Figure 2. Effect of sodium hydroxide ammount and time for roasting process.

catalyst was greater than 0.1 , the leaching rate increased significantly, and when the ratio reached 0.4 , the leaching efficiency of tungsten reached a maximum, while vanadium leaching increase was insignificant. Therefore, a 0.4 ratio of $\mathrm{NaOH} /$ feedstock is considered as optimum for further experiments. In the case of silicon leaching, according to the Le-Chatelier principle, if the amount of $\mathrm{NaOH}$ is greater the equilibrium will go towards the formation of products, which in the case include silicon compounds. Thus, a minimization of the amount of $\mathrm{NaOH}$ used while maximizing the vanadium and tungsten leached will lead to the minimization of the silicon compounds produced. As analyzed in the previous section, when $\mathrm{NaOH}$ solution is used as a roasting agent the amount of $\mathrm{Si}$ leached is smaller, therefore at a reduced concentration of $\mathrm{NaOH}$ silicon compound production will be smaller than in the case of $\mathrm{NaOH}$ solid used as a roasting agent. 
Effects of roasting time. To compare the leaching ability of vanadium and tungsten according to the roasting time, roasting was performed for 30 to $180 \mathrm{~min}$, followed by leaching. As shown in Fig. 2b, leaching efficiency of vanadium increases as the roasting time increases, and the tungsten leaching reaches a maximum after $120 \mathrm{~min}$. Due to the low concentration of vanadium in the original sample and the goal of this investigation being minimizing the amount of water soluble silicon compounds produced during roasting, $120 \mathrm{~min}$ is established as the ideal roasting time.

Effect of pulp density for leaching. Various experiments were used to examine how the pulp density influence in the leaching at $298 \mathrm{~K}$ and $300 \mathrm{rpm}$ for a sufficient time to have complete leaching (120 min). As shown in Fig. 3a, the pulp density does not have a great influence in the leaching efficiency; still, the highest leaching efficiency was at $30 \%$ pulp density. While, above $40 \%$, the leaching efficiency decreases. It is expected that if the amount of spent catalyst used is higher, the concentration of vanadium and tungsten leached will be higher too, however, as noticed in Fig. 3a the leaching efficiency does not improve with the increase of the pulp density. Thus, for an ideal mass transfer $30 \%$ pulp density was set as the optimum condition.

Effect of leaching time. The effect of the leaching time from 10 to $180 \mathrm{~min}$ in the leaching efficiency of vanadium and tungsten was explored. After soda roasting at $973 \mathrm{~K}$ for $120 \mathrm{~min}, 100 \mathrm{~mL}$ of distilled water was used for leaching from 10 to $180 \mathrm{~min}$ at $298 \mathrm{~K}, 300 \mathrm{rpm}$, and $30 \%$ pulp density. As shown in Fig. 3b, the leaching time does not contribute significantly to the leaching efficiency for vanadium and tungsten. Several researchers have studied the ideal conditions for roasting and leaching of spent SCR catalyst, however leaching time has always been long (at least $1 \mathrm{~h}$ ) to maximize the leaching of vanadium and tungsten ${ }^{19,20,24,25}$. For instance, Moon et al. obtained an almost complete leaching of vanadium and tungsten in a $1 \mathrm{~h}$ interval, however they did not consider the amount of silicon leached alongside the title metals ${ }^{26}$. Wu et al. did an alkaline leaching without a preprocessing (soda roasting) of the catalyst which has the disadvantage of a great consumption of alkali in the process and it takes 180 min to maximize the leaching efficiency of the valuable metals ${ }^{19}$. On the other hand, the process studied in this investigation reaches a maximum leaching efficiency of tungsten and vanadium in $30 \mathrm{~min}$ with the additional advantage of the minimization of the silicon compounds leached. As observed in Fig. 4c3 the fiber glass matrix (composed mostly of silicon oxide) after leaching keeps its structure, which shows the possibility of more formation of water soluble silicon compounds, thus minimizing the leaching time is imperative to minimize the silicon leached. It is deduced that vanadium and tungsten were converted into easily soluble compounds during the soda roasting process using $\mathrm{NaOH}$ aqueous and that facilitated the following leaching.

Effect of temperature for leaching. In the leaching process, the reaction temperature affects the mass transfer activity of the water-soluble target metals and acts as an important factor to determine the amount of metals leached. The effect of leaching temperature on leaching efficacy of vanadium and tungsten was studied in a range between 298 and $343 \mathrm{~K}$. As shown in Fig. 3c, the leaching efficiency for both title elements does not show a significant correlation with the temperature in the leaching process, this fact leads to the conclusion that from an economic standpoint $298 \mathrm{~K}$ will be used as the optimum leaching temperature. Moreover, it has been studied by various authors that as the reaction temperature increases, the activities of substances other than vanadium and tungsten in the spent catalyst increase $e^{2,19,23,27}$, therefore a lower temperature $(298 \mathrm{~K})$ is preferred to avoid an increase in the leaching of silicon or any other impurity.

Morphology of the samples at different metal recovery stages. SEM-EDS images were taken for the raw spent SCR catalyst, after roasting and after leaching to compare the morphology of the residues at different stages. Figure 4 shows the SEM images at different magnifications for the original spent SCR catalyst, the spent SCR catalyst roasted with dissolved $\mathrm{NaOH}$ and the residue after leaching. Figure 4a1,b1,c1 show the spent catalyst sample before roasting, after roasting and after leaching at low magnification, respectively. It can be observed that in the case of the raw spent catalyst (a1) there is a clear presence of fiber glass rods (silica, alumina and calcium oxide) which are the main concern for this research due to the minimization of silica leaching as a primary research goal. As observed in the posterior EDS figures it is clear that the particles surrounding the glass fiber rods are composed mainly of titanium oxide (anatase form), vanadium and tungsten while the primary structure of the rod is silica. In Fig. $4 \mathrm{~b} 1, \mathrm{cl}$ the rods are not clear in shape at low magnification due to the crushing done with mortar and pestle to the roasted residue before leaching.

When the magnification is increased 1000 times, it can be observed that in Fig. 4a2,b2 there is some agglomeration on the rod type structures while in Fig. 4c) the rod structures show a smooth texture. In the largest magnification Fig. 4a3,b3,c3, it can be observed in the original spent catalyst an agglomeration on top of the fiber glass road which being analyzed by EDS it is attributed to the presence of vanadium and tungsten in the fiber glass matrix of the spent catalyst. Moreover, in Fig. $4 \mathrm{~b} 3$ there is agglomeration over the rod-type structure, which when analyzed with EDS it shows the formation of a layer of sodium compounds formed on the fiberglass matrix. Finally in Fig. 4c3, a smooth texture is observable characteristic of fiber glass surface, which leads to the deduction that vanadium and tungsten sodium compounds were leached from the surface leaving the fiber glass(composed of calcium, aluminum and silicon) in its original shape.

In Fig. 5 corresponding to the EDS analysis of the raw spent SCR catalyst it can be appreciated that there is a clear silicon and calcium rod structure in the middle covered mainly in tungsten. Moreover, vanadium and titanium are spread along the sample, the presence of titanium around the rod type structures and spread is in accordance with the main component of SCR catalyst that is $\mathrm{TiO}_{2}$ (anatase phase).

Figure 6 shows the catalyst EDS analysis after roasting, an agglomeration of sodium particles can be observed covering the fiber glass rod which indicate the formation of sodium compounds such as sodium vanadate and 
(a)

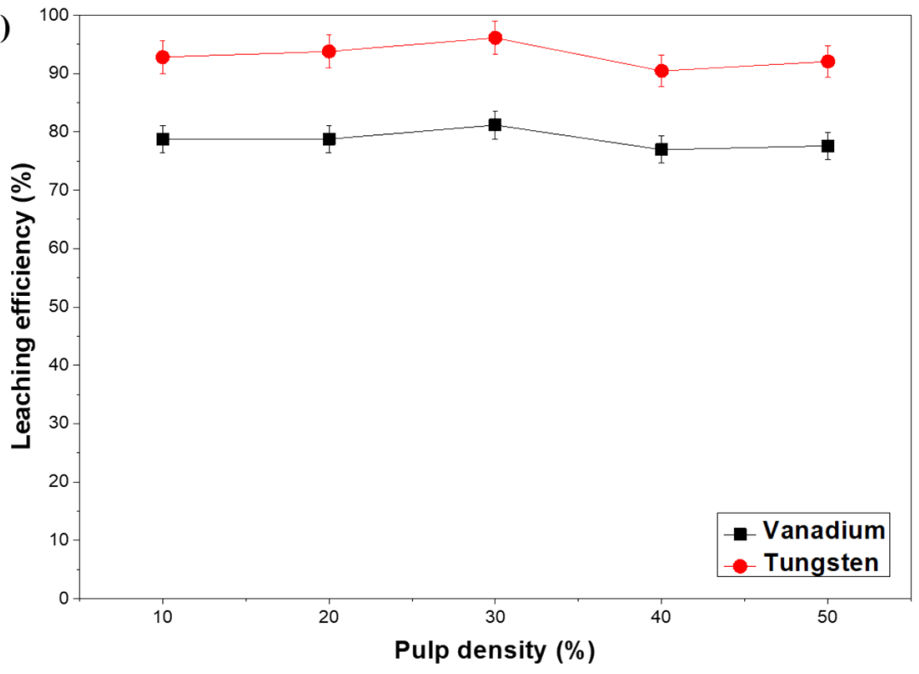

(b)

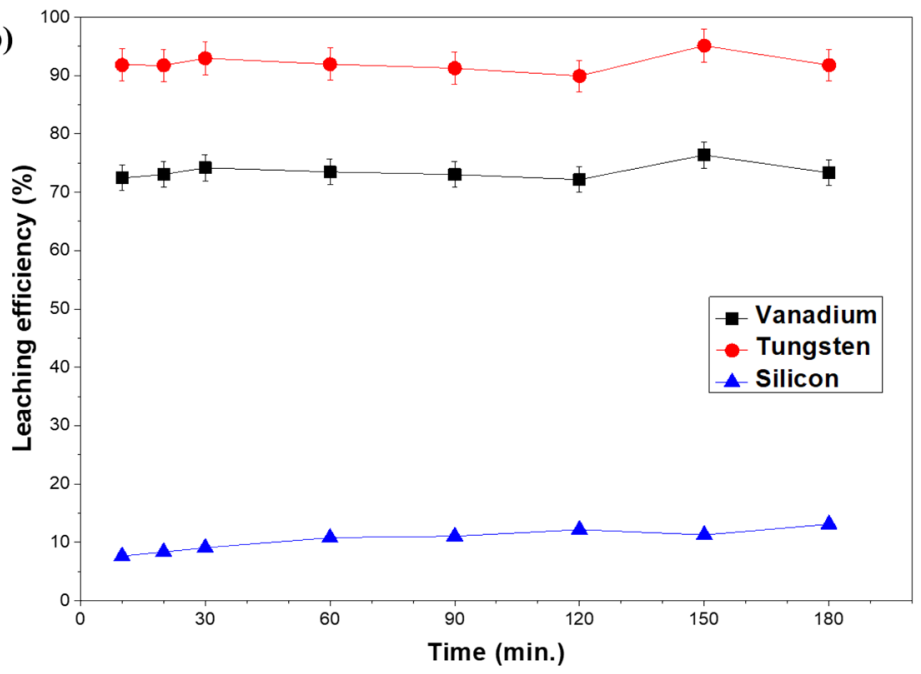

(c)

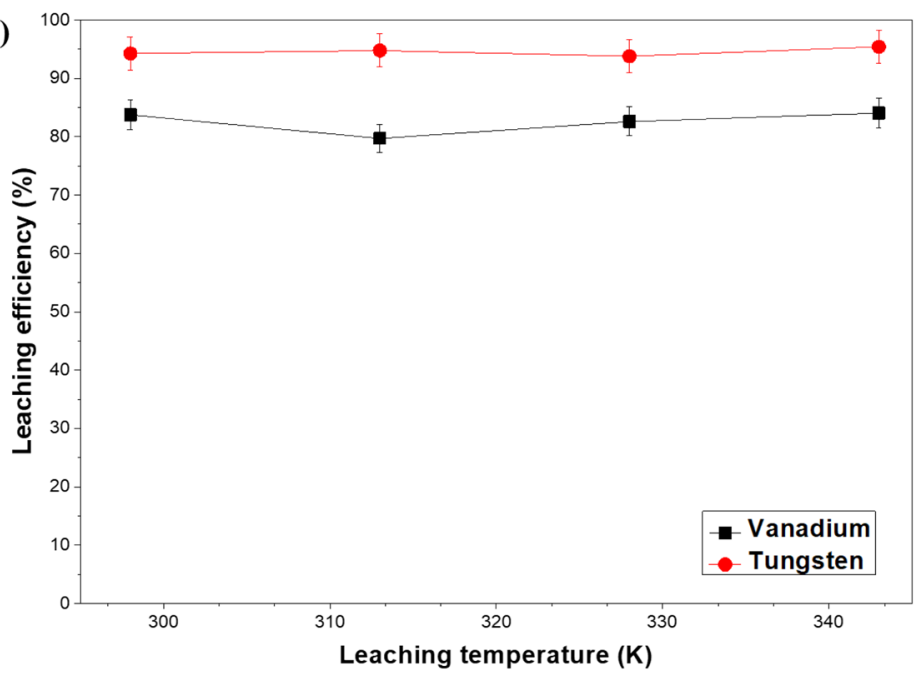

Figure 3. Effect of pulp density (a), time (b), and temperature (c) for leaching of the spent SCR catalyst. 


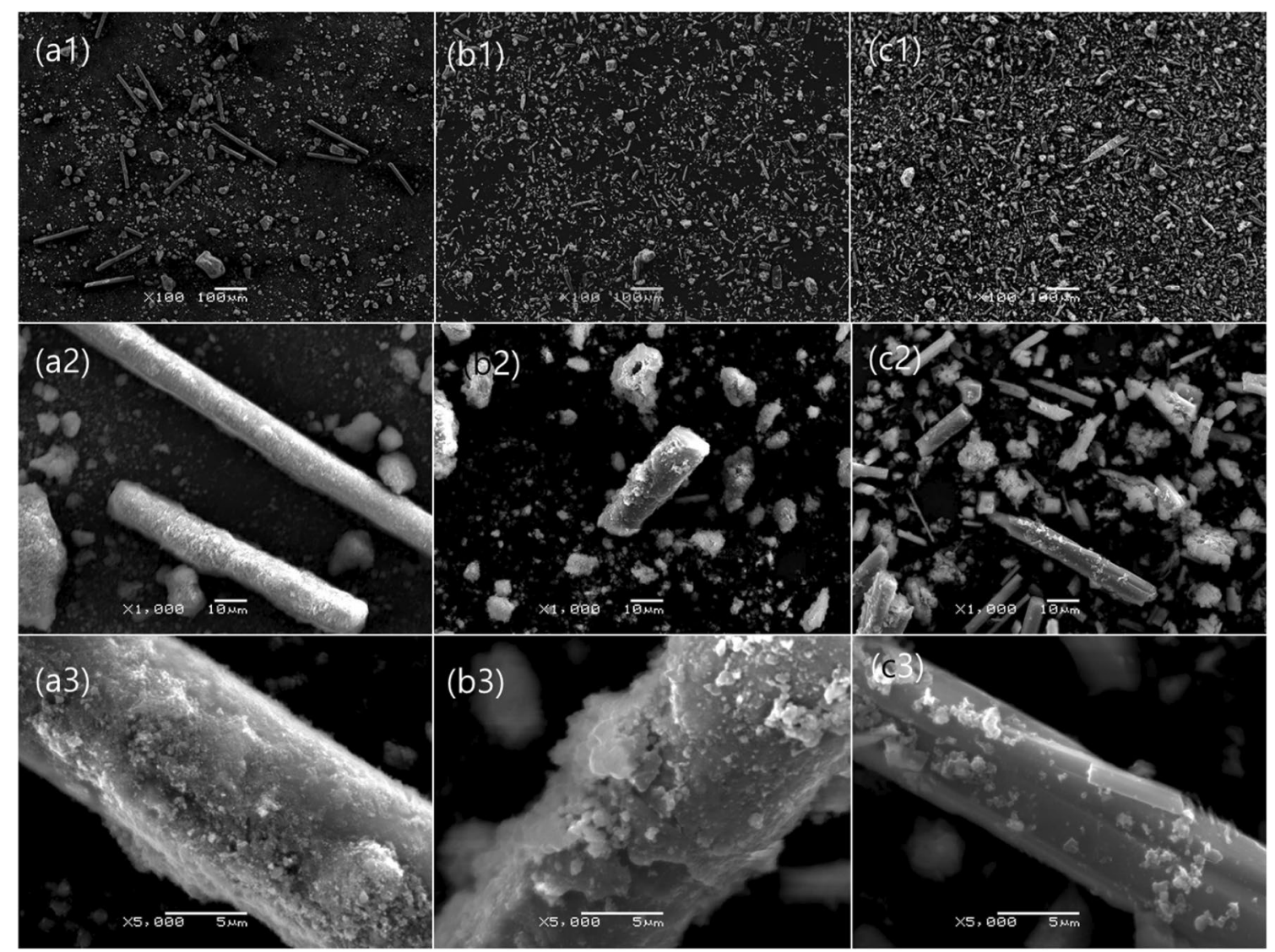

Figure 4. SEM images of (a) raw spent SCR catalyst, (b) soda roasted spent SCR catalyst and (c) residue obtained when water leaching was conducted at $298 \mathrm{~K}$.
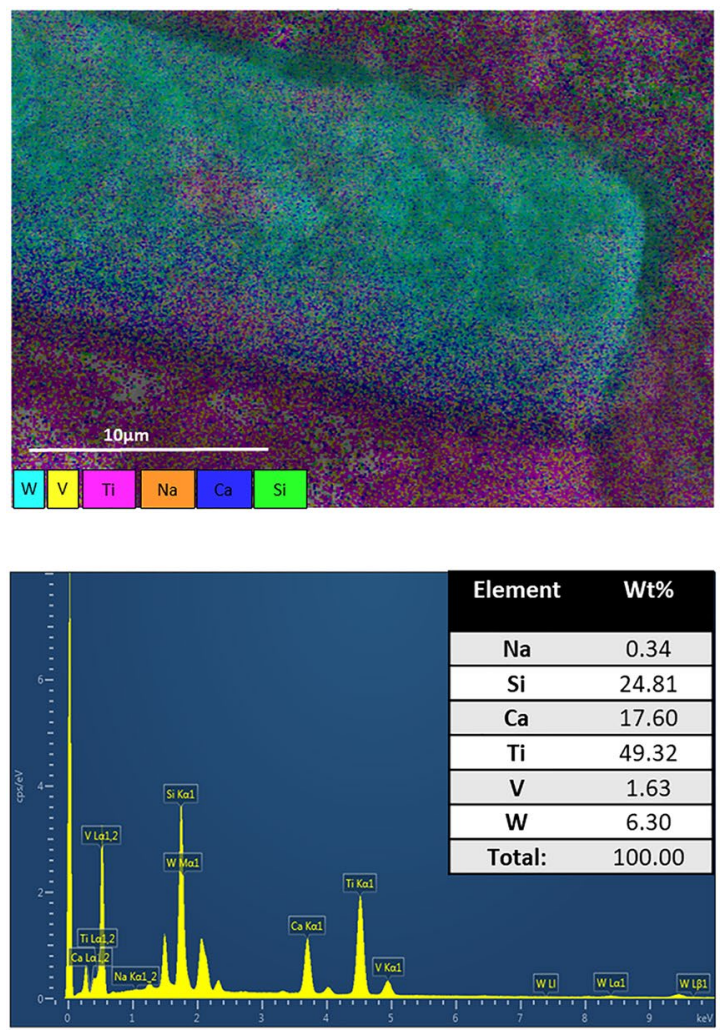

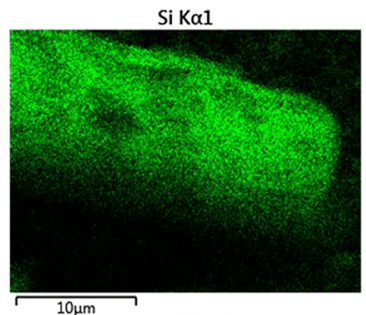

Ca K $\alpha 1$
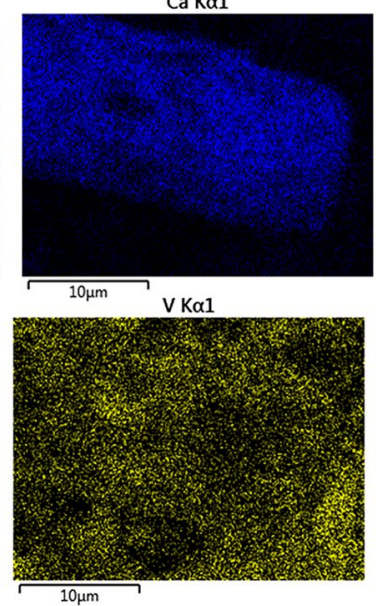

Figure 5. SEM-EDS images and element composition of raw spent SCR catalyst. 

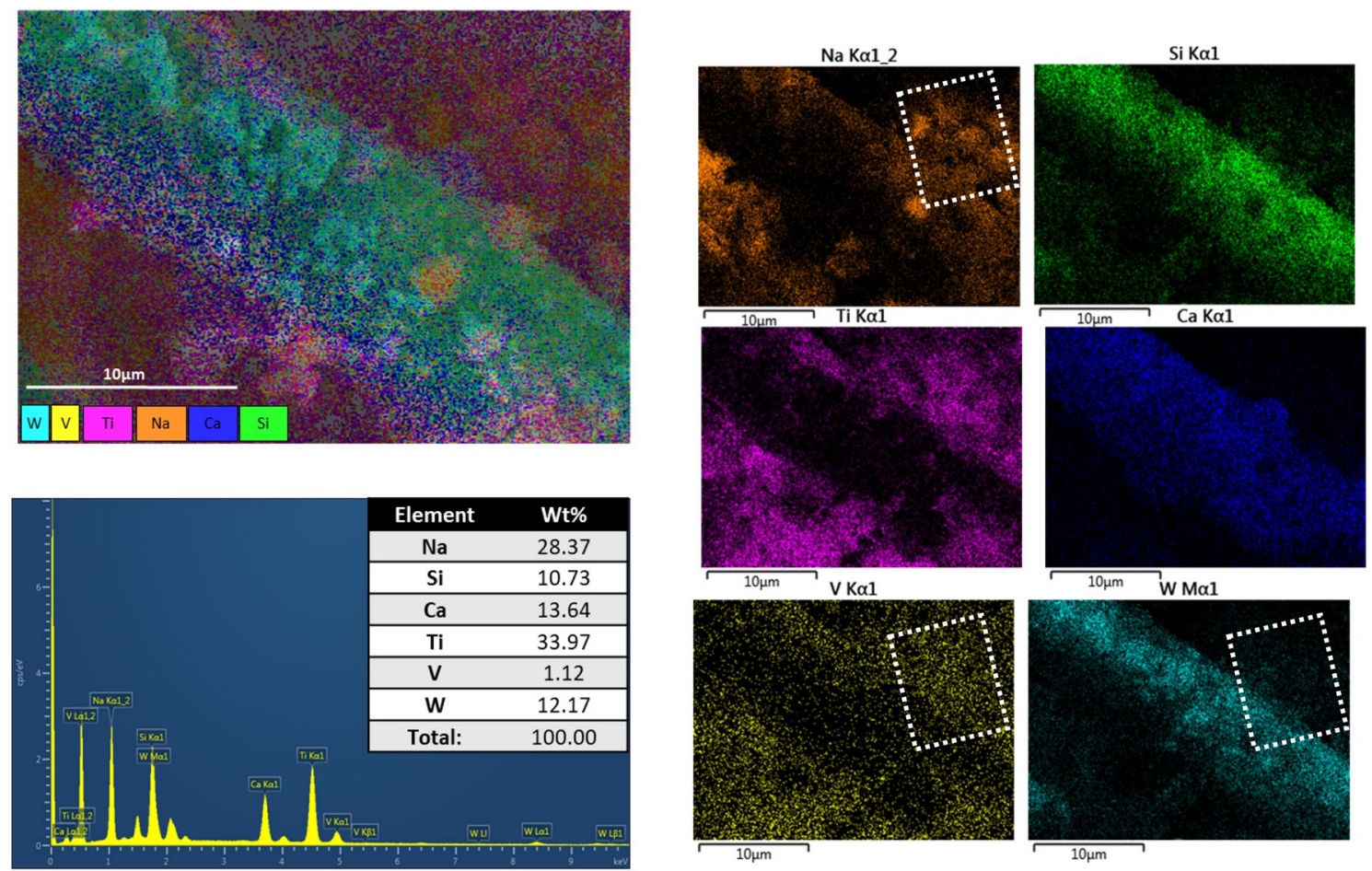

Figure 6. SEM-EDS images and element composition of roasted spent SCR catalyst.

tungstate. However, due to the large presence of sodium all over the rod-like structure, it can be deducted that some $\mathrm{Na}_{2} \mathrm{SiO}_{3}$ might have been formed, but due to the uniformity and the high surface area for reaction of $\mathrm{NaOH}$ solution with vanadium and tungsten there is a layer formed on top of the fiberglass matrix inhibiting a high leaching of silicon compounds. Moreover, the percentage of sodium in the sample has increased in accordance to the reaction with the metals present.

It is observable in the EDS patterns in Fig. 7 that after leaching the density of sodium particles present in the sample decreases, while the percentage of vanadium almost keeps constant (due to the small initial presence of this element) but tungsten decreases significatively. Moreover, the percentage of silicon compounds varies, which is in accordance to the results obtained in the roasting and leaching parameters analyzed previously. In addition, the morphology of the sample keeps the rod-type structure without a great change in shape or dimensions, which leads to the conclusion that a smaller amount of silicon was leached when $\mathrm{NaOH}$ solution is used as a roasting agent, in addition some small agglomeration of particles on top of the fiberglass is indicative of vanadium and tungsten not leached during the process.

\section{Experimental}

Feedstock. The raw spent SCR catalyst was obtained from the thermoelectric power plant in Samcheonpo, South Korea. The samples were grinded to a size of less than $100 \mu \mathrm{m}$, in addition to removing the dust and contaminants on the surface before experiments. The crushed spent catalyst samples were desiccated at $100^{\circ} \mathrm{C}$ for a day. The composition of the feedstock used in the experiment is shown in Table 1, and the XRD diagram is shown in Fig. 8.

Soda roasting and leaching. Sodium hydroxide ( $\mathrm{NaOH}$, supplied by Junsei Chemical, $99 \%$ purity, Japan) was used for the soda roasting of the spent SCR deNO $\mathrm{x}_{\mathrm{x}}$ catalyst. $\mathrm{NaOH}$ reacts with insoluble $\mathrm{V}_{2} \mathrm{O}_{5}$ and $\mathrm{WO}_{3}$ to obtain soluble compounds $\left(\mathrm{NaVO}_{3}, \mathrm{Na}_{2} \mathrm{WO}_{4}\right)$ by soda roasting from spent $\mathrm{SCR}$ deNO $\mathrm{N}_{\mathrm{x}}$ catalysts. In order to compare the efficiency according to the state (solid or liquid) of $\mathrm{NaOH}$ used as a roasting agent, solid $\mathrm{NaOH}$ was grinded and mixed with the spent SCR catalyst and placed in an alumina crucible. On the other hand, dissolved $\mathrm{NaOH}$ was mixed with the spent SCR catalyst and stabilized for $10 \mathrm{~min}$ to wet the solid totally in an alumina crucible in preparation for the roasting process. The amount of $\mathrm{NaOH}$ added was 10 to $50 \%$ by weight, depending on the weight of the feedstock, and roasted in a muffle furnace without any gas or air inlet for $2 \mathrm{~h}$ while varying the temperature conditions. The roasting experiments were performed at temperatures ranging 773 to $1173 \mathrm{~K}$ and time variation from 30 to $180 \mathrm{~min}$ to understand the effect of the reaction temperature and reaction time. After soda roasting, the cooled sample was placed in a Teflon reactor and leaching experiments were performed on a hot plate modifying different conditions such as pulp density, temperature and reaction time. The overall process for spent SCR catalyst is depicted in Fig. 9.

Analysis. To obtain the concentration of the title elements (V, W, Si) in the leach liquor an inductively coupled plasma optical emission spectrometer (ICP-OES, Optima 8500, USA) was used. The composition of the 

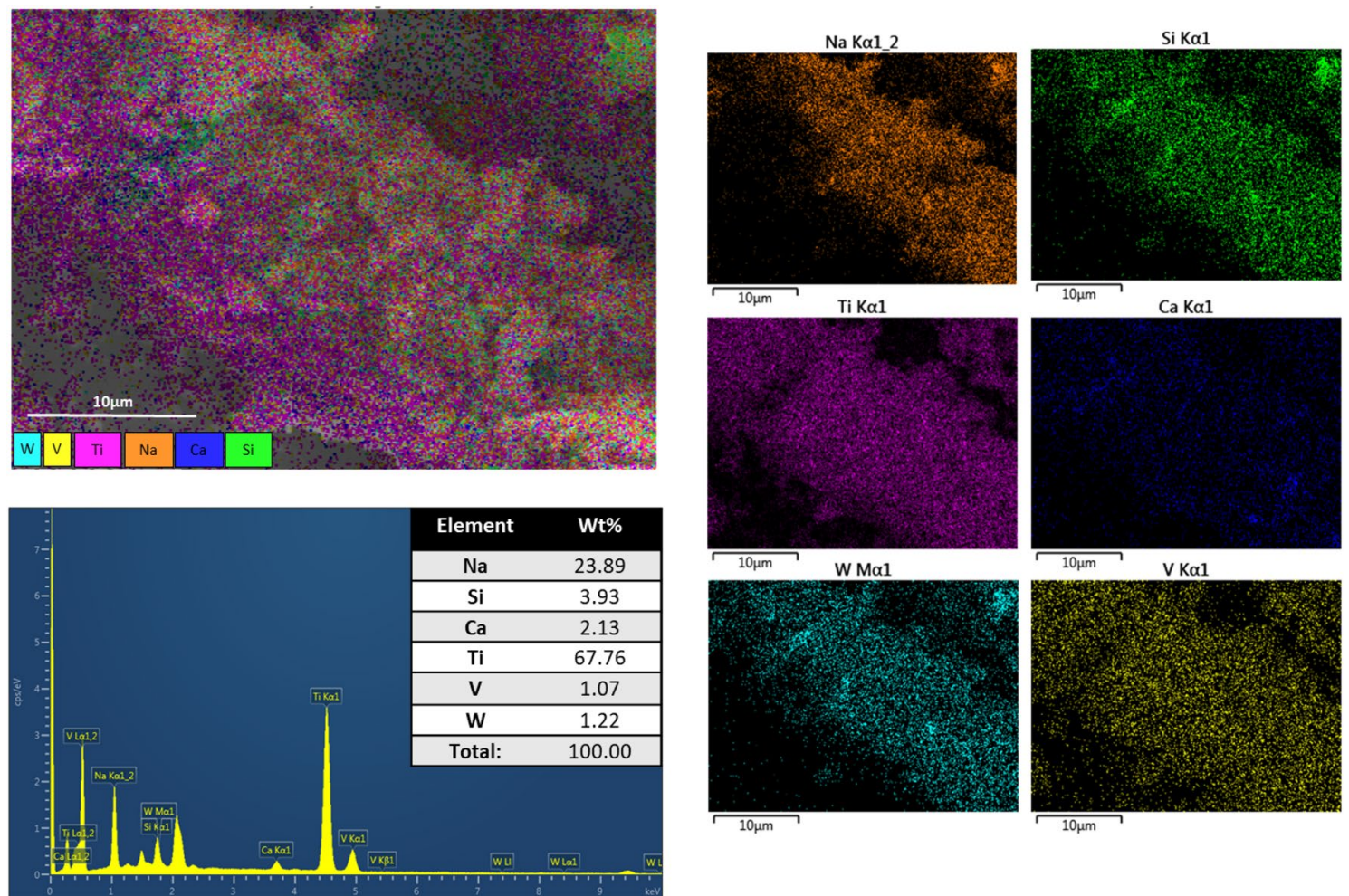

Figure 7. SEM-EDS images and element composition of leached catalyst.

\begin{tabular}{|l|l|l|l|l|l|l|l|l|l|l|}
\hline Component & $\mathrm{TiO}_{2}$ & $\mathrm{SiO}_{2}$ & $\mathrm{WO}_{3}$ & $\mathrm{Al}_{2} \mathrm{O}_{3}$ & $\mathrm{CaO}$ & $\mathbf{V}_{2} \mathbf{O}_{5}$ & $\mathrm{FeO}$ & $\mathrm{MgO}$ & $\mathrm{MoO}_{3}$ & $\mathrm{H}_{2} \mathrm{O}$ \\
\hline Wt.\% & 70.9 & 9.80 & 7.73 & 5.57 & 2.50 & 1.23 & 0.77 & 0.55 & 0.10 & 0.85 \\
\hline
\end{tabular}

Table 1. Elemental composition of spent SCR catalyst.

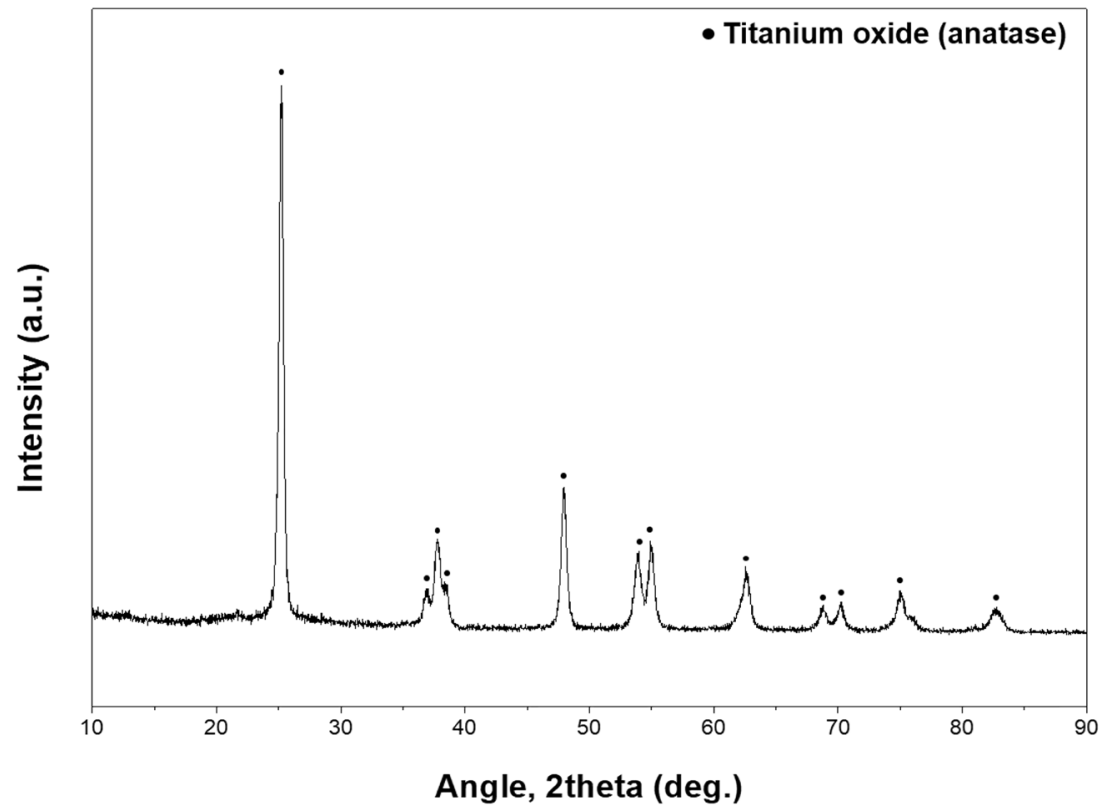

Figure 8. XRD pattern of spent SCR catalyst. 

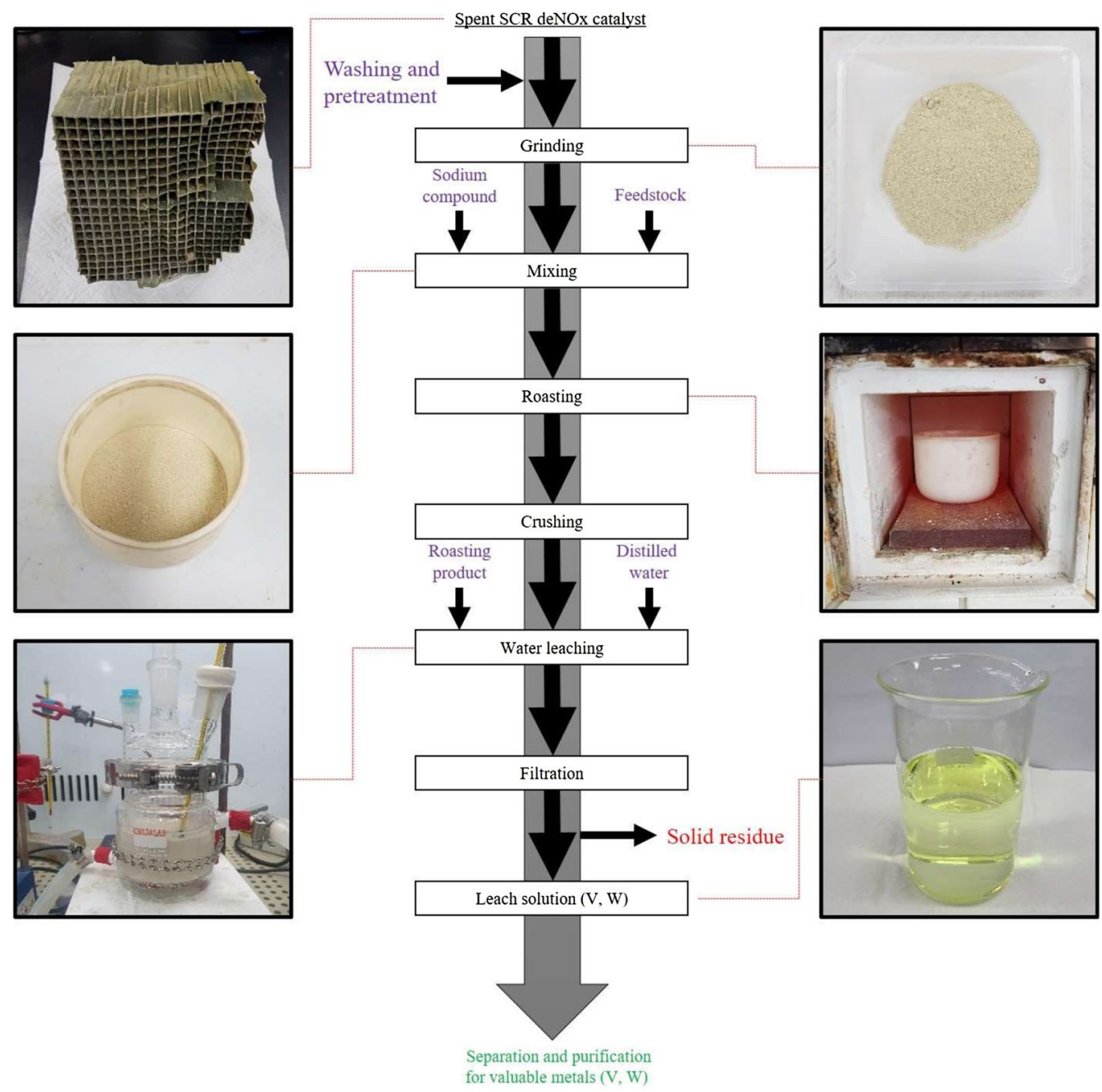

for valuable metals $(\mathrm{V}, \mathrm{W})$

Figure 9. Eco- friendly hydrometallurgical process flowsheet for spent $\mathrm{SCR} \mathrm{DeNO}_{\mathrm{x}}$ catalyst leaching.

raw sample and residues of spent SCR catalyst was analyzed by X-ray diffractometer (XRD, Rigaku, Japan). The scanning electron microscope and energy Dispersive Spectrometer (SEM-EDS, JSM-6380LA, Japan) was used to analyze the surface and composition of samples.

\section{Conclusions}

Due to the environmental risk that spent SCR catalyst pose when discarded in landfills and the presence of valuable metals such as vanadium and tungsten, there is a big necessity for recycling of these secondary resources. During the present research the roasting process of spent SCR catalyst was optimized comparing $\mathrm{NaOH}$ dry roasting and aqueous roasting using $\mathrm{NaOH}$ solution as a roasting agent. The main goal of the investigation is to maximize the leaching efficiency of both metals while minimizing the silicon compounds leached into the pregnant solution. The optimum conditions for roasting are 0.4 mass ratio of $\mathrm{NaOH} /$ spent $\mathrm{SCR}$ catalyst solution for $2 \mathrm{~h}$ at $973 \mathrm{~K}$. With a subsequent de-ionized water leaching for $30 \mathrm{~min}$, at $298 \mathrm{~K}$ with a pulp density of $30 \%$. At the optimum conditions there was a leaching efficiency of $95.4 \pm 3 \%$ of tungsten while the vanadium leaching efficiency ranged in $80.2 \pm 3 \%$. Research results showed that using $\mathrm{NaOH}$ solution as the roasting agent reduced the posterior leaching of silicon compounds and it was observed that at the optimal roasting conditions the amount of silica leached was approximately half than when using dry $\mathrm{NaOH}$ as a roasting agent.

Received: 29 June 2021; Accepted: 1 November 2021

Published online: 11 November 2021

\section{References}

1. Nakajima, F. \& Hamada, I. The state-of-the-art technology of NOx control. Catal. Today 29, 109-115 (1996).

2. Jyothi, R. K., Moon, G., Kim, H.-R., Lee, J.-Y. \& Choi, I. H. Spent V2O5-WO3/TiO2 catalyst processing for valuable metals by soda roasting-water leaching. Hydrometallurgy 175, 292-299 (2017). 
3. Forzatti, P. Present status and perspectives in de-NOx SCR catalysis. Appl. Catal. A Gen. 222, 221-236 (2001).

4. Zhang, Q., Wu, Y. \& Yuan, H. Recycling strategies of spent $\mathrm{V}_{2} \mathrm{O}_{5}-\mathrm{WO}_{3} / \mathrm{TiO}_{2}$ catalyst: A review. Resour. Conserv. Recycl. 161, 104983 (2020).

5. Kim, H. I., Moon, G., Choi, I. H., Lee, J. Y. \& Jyothi, R. K. Hydrometallurgical process development for the extraction, separation and recovery of vanadium from spent desulfurization catalyst bio-leach liquors. J. Clean. Prod. 187, 449-458 (2018).

6. Zhang, F. et al. Selective separation of thorium from rare earths and uranium in acidic solutions by phosphorodiamidate-functionalized silica. Chem. Eng. J. 392, 123717 https://doi.org/10.1016/j.cej.2019.123717(2020).

7. Marafi, M. \& Stanislaus, A. Spent catalyst waste management: A review. Part I-Developments in hydroprocessing catalyst waste reduction and use. Resour. Conserv. Recycl. 52, 859-873 (2008).

8. Marafi, M. \& Stanislaus, A. Spent hydroprocessing catalyst management: A review. Part II. Advances in metal recovery and safe disposal methods. Resour. Conserv. Recycl. 53, 1-26 (2008).

9. Brandin, J. G. M. \& Odenbrand, C. U. I. Poisoning of SCR catalysts used in municipal waste incineration applications. Top. Catal. 60, 1306-1316 (2017).

10. Choi, I. H., Kim, H. R., Moon, G., Jyothi, R. K. \& Lee, J. Y. Spent $\mathrm{V}_{2} \mathrm{O}_{5}-\mathrm{WO}_{3} / \mathrm{TiO}_{2}$ catalyst processing for valuable metals by soda roasting-water leaching. Hydrometallurgy 175, 292-299 (2018).

11. Imtiaz, M. et al. Vanadium, recent advancements and research prospects: A review. Environ. Int. 80, 79-88 (2015).

12. Choi, I. H. et al. Recent developments in the recycling of spent selective catalytic reduction catalyst in South Korea. Catalysts 10, 182 (1-20) https://doi.org/10.3390/catal10020182 (2020).

13. Zhang, W., Qi, S., Pantaleo, G. \& Liotta, L. F. $\mathrm{WO}_{3}-\mathrm{V}_{2} \mathrm{O}_{5}$ active oxides for NOx SCR by NH3: Preparation methods, catalysts' composition, and deactivation mechanism-a review. Catalysts $\mathbf{9 ,} 527$ (2019).

14. Ye, X. et al. Microwave sodium roasting (MWSR) spent HDS catalysts for recovery Mo and in situ sulfur fixation. J. Taiwan Inst. Chem. Eng. 97, 146-157 (2019).

15. Choi, I. H., Moon, G., Lee, J. Y. \& Jyothi, R. K. Alkali fusion using sodium carbonate for extraction of vanadium and tungsten for the preparation of synthetic sodium titanate from spent SCR catalyst. Sci. Rep. 9, 1-8 (2019).

16. Choi, I. H., Moon, G., Lee, J. Y. \& Jyothi, R. K. Extraction of tungsten and vanadium from spent selective catalytic reduction catalyst for stationary application by pressure leaching process. J. Clean. Prod. 197, 163-169 (2018).

17. Ferella, F. A review on management and recycling of spent selective catalytic reduction catalysts. J. Clean. Prod. 246, 118990 (2020).

18. Wu, W. C., Tsai, T. Y. \& Shen, Y. H. Tungsten recovery from spent SCR catalyst using alkaline leaching and ion exchange. Minerals 6, 107 (1-10) https://doi.org/10.3390/min604010 (2016).

19. Wu, W., Wang, C., Bao, W. \& Li, H. Selective reduction leaching of vanadium and iron by oxalic acid from $\mathrm{spent}_{2} \mathrm{~V}_{2} \mathrm{O}_{5}-\mathrm{WO}_{3} / \mathrm{TiO} \mathrm{O}_{2}$ catalyst. Hydrometallurgy 179, 52-59 (2018).

20. Choi, I. H., Moon, G., Lee, J. Y. \& Jyothi, R. K. Hydrometallurgical processing of spent selective catalytic reduction (SCR) catalyst for recovery of tungsten. Hydrometallurgy 178, 137-145 (2018).

21. Cueva Sola, A. B., Parhi, P. K., Thenepalli, T. \& Jyothi, R. K. Rare-Earth Metal Recovery for Green Technologies. Rare-Earth Metal Recovery for Green Technologies (Springer, New York, 2020). https://doi.org/10.1007/978-3-030-38106-6.

22. Ferella, F., Innocenzi, V. \& Maggiore, F. Oil refining spent catalysts: A review of possible recycling technologies. Resour. Conserv. Recycl. 108, 10-20 (2016).

23. Su, Q. et al. Optimizing vanadium and tungsten leaching with lowered silicon from spent SCR catalyst by pre-mixing treatment. Hydrometallurgy 181, 230-239 (2018).

24. Yao, J. et al. Successive calcination-oxalate acid leaching treatment of spent SCR catalyst: A highly efficient and selective method for recycling tungsten element. Hydrometallurgy 201, 105576 (2021).https://doi.org/10.1016/j.hydromet.2021.105576 (2021).

25. Cao, Y., Yuan, J., Du, H., Dreisinger, D. \& Li, M. A clean and efficient approach for recovery of vanadium and tungsten from spent SCR catalyst. Miner. Eng. 165, 106857 (2021).

26. Moon, G., Kim, J. H., Lee, J. Y. \& Kang, J. Leaching of spent selective catalytic reduction catalyst using alkaline melting for recovery of titanium, tungsten, and vanadium. Hydrometallurgy 189, 105132 (2019).

27. Luo, L., Miyazaki, T., Shibayama, A., Yen, W. \& Fujita, T. A novel process for recovery of tungsten and vanadium from a leach solution of tungsten alloy scrap. Miner. Eng. 16, 665-670 (2003).

\section{Acknowledgements}

This study was supported by the R\&D Center for Valuable Recycling (Global-Top R\&D Program) of the Ministry of Environment (Project Number: 2019002230001), Korea.This work was supported by Korea Institute of Energy Technology Evaluation and Planning(KETEP) grant funded by the Korea government(MOTIE)(20217510100020, Development of platform process using common core and materialization technology for rare metal recovery from industrial low-grade waste liquid).

\section{Author contributions}

Dr. J.H.J. did all the experiments and wrote the manuscript. Ms. A.B.C.S. did the formal analysis of the SEM and SEM-EDS data and edited the manuscript, Prof. J.-Y.L.and Prof. R.K.J. supervised the experiments, did the formal analysis, and edited the manuscript.

\section{Competing interests}

The authors declare no competing interests.

\section{Additional information}

Correspondence and requests for materials should be addressed to R.K.J.

Reprints and permissions information is available at www.nature.com/reprints.

Publisher's note Springer Nature remains neutral with regard to jurisdictional claims in published maps and institutional affiliations. 
(c) (i) Open Access This article is licensed under a Creative Commons Attribution 4.0 International cc) License, which permits use, sharing, adaptation, distribution and reproduction in any medium or format, as long as you give appropriate credit to the original author(s) and the source, provide a link to the Creative Commons licence, and indicate if changes were made. The images or other third party material in this article are included in the article's Creative Commons licence, unless indicated otherwise in a credit line to the material. If material is not included in the article's Creative Commons licence and your intended use is not permitted by statutory regulation or exceeds the permitted use, you will need to obtain permission directly from the copyright holder. To view a copy of this licence, visit http://creativecommons.org/licenses/by/4.0/.

(C) The Author(s) 2021 